\title{
Marked geographic patterns in the incidence of idiopathic central precocious puberty: a nationwide study in France
}

\author{
Joëlle Le Moal ${ }^{1, *}$, Annabel Rigou ${ }^{1, *}$, Alain Le Tertre', Perrine De Crouy-Channel', Juliane Léger ${ }^{3}$ and \\ Jean-Claude Carel ${ }^{3}$ \\ ${ }^{1}$ Environmental Health Division, Santé publique France, Saint-Maurice, France, ${ }^{2}$ Assistance Publique-Hôpitaux de \\ Paris (AP-HP), Hôpital Universitaire Robert-Debré, Department of Pediatric Endocrinology and Diabetology, and \\ Centre de Référence des Maladies Endocriniennes Rares de la Croissance F-75019, Paris, France, and ${ }^{3}$ PROTECT, \\ INSERM, Université Paris Diderot, Sorbonne Paris Cité, F-75019 Paris, France \\ *(J Le Moal and A Rigou contributed equally to this work)
}

Correspondence should be addressed to L M Joëlle

Email

joelle.lemoal@ santepubliquefrance.fr

\section{Abstract}

Objectives: Precocious puberty seems to be increasing but epidemiological data are scarce. Our objective was to improve the epidemiologic knowledge on this disease. We analyzed the national incidence and spatial trends of idiopathic central precocious puberty in France in 2011-2013 in a cross-sectional descriptive study.

Design: We used an indicator based on treatment reimbursements recorded in the national insurance database, in girls under the age of nine years and in boys under the age of 10 years. We considered a time lag of up to one year from the onset of puberty to first drug delivery. We tested four different predictive spatial models at the département scale, selecting the model best fitting the data. We carried out semi-structured interviews with qualified hospital teams in five selected regions to investigate spatial differences in medical practices.

Results: The national annual incidence was 2.68 (95\% Cl: 2.55, 2.81) per 10000 girls under the age of 9 years and $0.24(95 \% \mathrm{Cl}: 0.21,0.27)$ per 10000 boys under the age of 10 years. Incidence rates conformed to a purely spatial heterogeneity model in girls, consistent between age groups, with a large incidence range. A similar pattern was observed for boys, with peaks in the South West and Center East. Differences in medical practices may have slightly affected incidence locally, but could not entirely explain the marked geographic pattern. Conclusions: The results suggest that the risk factors are similar for boys and girls and justify further investigations of the role of the environment.

\section{Introduction}

A secular trend toward a gradual advance in the timing of puberty has been reported (1). This trend has been associated with the obesity epidemic (2), and exposure to endocrine disrupting chemicals (EDCs) has also been identified as a possible causal factor (3).

Santé publique France, the French national public health agency, carries out epidemiological monitoring (4) for nationwide health indicators selected on the basis of their proven or suspected links to EDC exposure, using existing databases. The aim is to analyze time
() 2017 European Society of Endocrinology Printed in Great Britain
European Journal of Endocrinology (2018) 178, 33-41 
in France, as suggested by clinicians' observations, and as reported in other countries $(6,7)$.

Very few epidemiological studies have been carried out on PP worldwide $(7,8,9)$. PP is defined in Europe (10) by the occurrence of pubertal development before the age of eight years in girls and nine years in boys and is much more frequent in girls than that in boys, with a femaleto-male sex ratio of 3 to 20 (6). This disease is associated with shorter adult height and health risks in adult life, including reproductive cancers, cardiovascular diseases and psychological problems $(11,12)$. Some genetic factors have been identified $(10,13)$ but environmental factors have also been implicated in its onset (14). Central PP (CPP), which is treated specifically with gonadotrophinreleasing hormone (GnRH) agonists, accounts for four in five cases of PP and is much more frequently seen in girls than in boys (6). This form results from premature activation of the hypothalamic-pituitary-gonadal axis (15). It is mostly idiopathic central PP (ICPP), but may originate from identified central nervous system lesions. Peripheral PP results from gonad lesions and is more frequent in boys.

There may be a causal link between ICPP, the most frequent subtype in girls (16) and EDC exposure. A similar mechanism may underlie the secular decrease in age at menarche in girls (6).

Our purpose was to improve the epidemiologic knowledge on this disease. We performed a descriptive study of the national incidence and spatial trends for ICPP in France, using an epidemiological indicator based on drug treatment data from the French National Health Insurance Information System (SNIIRAM).

\section{Methods}

\section{Data source}

All the data were obtained from SNIIRAM, which covers 98\% of the French population (65.2 million inhabitants in 2012). This database comprehensively records all hospital stays, prescriptions, health care services and reimbursed drug treatments, with their dates, sociodemographic data (age, sex, etc.) and a very precise area of residence for the patient (zipcode). This database provides data for the current year and the three preceding years (17).

We identified drugs on the basis of their Anatomical Therapeutic Classification codes. Medical information during hospitalization was encoded according to International Classification of Disease (ICD 10) codes. An anonymous and unique identification number for each patient linked all this information together. This number also made it possible to spot patients with several health care occurrences.

Access to the SNIIRAM databases was authorized by the Institute of Health Data (Institut des données de santé) and the French data protection agency (Commission nationale de l'informatique et des libertés).

\section{Selection of ICPP incident cases}

We selected all cases for which at least one reimbursement had been paid for GnRH agonists (see the list of products in Supplementary Table 1, see section on Supplementary Data given at the end of this article) in mainland France, for girls under the age of nine years and for boys under the age of ten years, taking into account a time lag of up to one year, from clinical onset to the first drug delivery (18). By linking reimbursement and hospital data, we excluded cases for which a cause of CPP had been identified (e.g. surgical intervention for brain tumors or other brain-related causes) and peripheral endocrine tumors (10), using ICD 10 codes associated with these conditions (list of codes in the data supplement). We also excluded cases treated with drugs used for peripheral causes of PP (e.g. congenital adrenal hyperplasia). Incident cases in a given year $n$ were defined as patients for whom no reimbursement for GnRH agonist was recorded during the year $n-1$. Data were available for theyears 2010-2013 and for the first six months of 2014. The study period was therefore 2011-2013 and the study design was cross-sectional.

\section{Data analysis}

We described the baseline characteristics of the study population by sex and age group. ICPP cases were counted by département (a French administrative district, equivalent to a county), for all ages and by age group [0-7], [7-8], [8-9] for girls, and for all ages for boys. We analyzed the data and their spatial distribution, with four different predictive models: a simple average based on an assumption of homogeneity over the entire country, unstructured heterogeneity implying true differences in rates unrelated to neighborhood with the addition of an unstructured spatial random effect to account for independent region-specific noise, purely structured spatial heterogeneity implying that the rate observed in a given neighborhood is affected by the rates in the 
surrounding neighborhood, by adding an intrinsic autoregressive term, often referred to as the CAR or Besag model and, finally, a model combining the two previous spatial random effects, i.e. structured and unstructured, and their implications. Besag (19) has provided a full description of these models. The deviance information criterion (DIC) was used to select the model that best fitted the data. National incidence and incidence by département were predicted, with 95\% credible intervals (95\% CI), with the best model selected on the basis of the DIC, from French population census data from the National Institute of Statistics and Economic Studies.

The results obtained with the model were input into GIS ArcGIS, version 10.0 software (ESRI) to chart spatial variations in the incidence of ICPP. We generated a map for each sex and for each age group, based on a manual classification of values.

\section{Semi-structured interviews with clinicians}

We investigated potential spatial differences in medical practices by conducting two-hour semi-structured interviews with five leading regional hospital teams of pediatric endocrinologists from contrasted regions with regard to incidence rates in March 2016. These interviews were carried out with a standardized guide developed with the assistance of an anthropologist-sociologist. We investigated the differences in practices concerning patient recruitment, diagnosis and prescriptions for ICCP between these regions. We also collected data on the doctors' perceptions concerning the incidence of ICPP in their region and their comments about our results. Each interview was carried out with two to seven team members, including the head of the team in each case. The hospital teams interviewed were not known to each other, minimizing bias.

\section{Results}

\section{Case descriptions}

From 2011 to 2013, we identified 3519 girls and 352 boys with ICPP in mainland France (Table 1), corresponding to about 1173 new cases per year in girls and 117 in boys. There was thus a female predominance (female-to-male ratio 10:1). The youngest age groups [0-8 years] in boys and [0-7 years] in girls (age at first date of delivery of GnRH agonist treatment) accounted for about $16 \%$ of all cases for each sex. The distribution of cases by age is presented, in years, in Fig. 1, the number of cases increasing with age for both sexes.
Table 1 Baseline characteristics of new ICPP cases with age at first delivery of GnRH agonist, 2011-2013, mainland France.

\begin{tabular}{lc}
\hline Age & $\boldsymbol{n}(\%)$ \\
\cline { 1 - 2 } \cline { 2 - 2 } Boys & $352(9.1)$ \\
$\quad$ Total $n$ & $55(15.63)$ \\
$0-8$ years & $81(23.01)$ \\
9 years & $216(61.36)$ \\
10 years & 9.11 \\
Mean age (years) & $3519(90.9)$ \\
Girls & $565(16.06)$ \\
Total $n$ & $1235(35.10)$ \\
$0-7$ years & $1719(48.85)$ \\
8 years & 8.21 \\
9 years & \\
Mean age (years) & \\
\hline
\end{tabular}

A
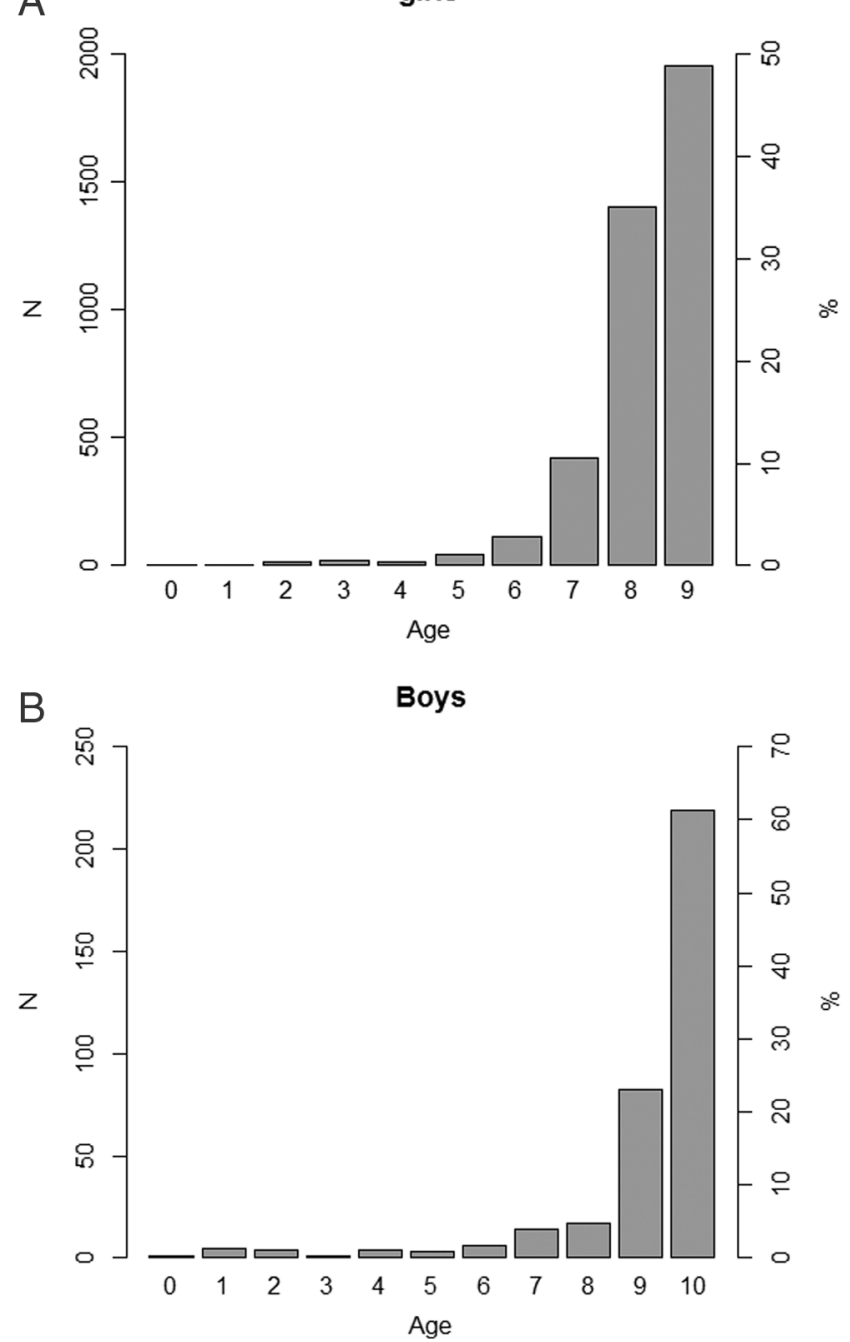

\section{Figure 1}

ICPP cases, by age at first delivery of GnRH agonist in years, in girls (1A) and boys (1B), 2011-2013, in France. 


\section{Annual fitted incidence rates for girls and boys, 2011-2013}

The incidence rate was 2.68 per 10000 girls under the age of nine years ( $95 \%$ CI: $2.55,2.81$ ).

The incidence rate per 10000 girls, and its 95\% CI, increased with age: $0.62(0.57,0.69)$ for the [0- to 7]-yearold group, $9.56(8.84,10.26)$ for the [7- to 8]-year-old group and $11.7(10.89,12.57)$ for the [8- to 9]-year-old group.

The incidence rate was 0.24 (95\% CI: $0.21,0.27$ ) per 10000 boys under the age of 10 years. Due to the small number of cases, it was not possible to apply the model to different age groups.

\section{Spatial distribution of ICPP incidence}

For girls of all ages and by age group, and for boys of all ages, DIC identified the best model as purely spatial heterogeneity.

Fitted incidences by département, for girls of all ages, ranged from 0.96 to 12.39 per 10000 girls (Fig. 2A). We observed excess incidences in the Southwest (MidiPyrénées) and Center East (Rhône-Alpes), with incidences 10.4-13 times higher than the lowest incidence recorded. A similar geographic pattern was obtained for boys (Fig. 2B). Fitted incidences ranged from 0.117 to 1.72 per 10000 boys. The highest incidences were 8.5-14.7 times higher than the lowest incidence.

Similar patterns were observed in various age groups of girls (Fig. 3), and the incidence in Midi-Pyrénées was particularly high for the (8-to 9)-year-old group. The highest incidences were 3.5, 7.9 and 23 times higher than the lowest incidences in the [0-7], [7-8] and [8-9] years age groups respectively.

\section{Clinical practices}

Table 2 in the Supplementary data summarizes the information recorded during the semi-structured interviews with clinicians. Overall, clinicians used similar criteria for diagnosis and treatment, mostly in accordance with a consensus statement published in 2009 (20). Nevertheless, we identified some noticeable processes. In one region with a high ICPP incidence, cases were referred to the tertiary care center through a network of trained general practitioners and pediatricians, a practice that is not developed throughout in the country. In another region with a high ICCP incidence, ICPP was diagnosed by determining LH in the first-voided urinary sample, a non-invasive method, rather than with the GnRH test generally used. In one region with a low incidence, clinicians relied heavily on surveillance, with consultations every three to six months to determine whether PP was progressive before proposing the GnRH test and, especially in girls over the age of seven years, treatment was limited to progressive ICPP.

In all regions, clinicians agreed that ICCP with an onset of puberty before the age of seven years in girls and nine years in boys was systematically treated with GnRH agonists. Practices were thought to be essentially homogeneous within each region.

\section{Discussion}

We here provide the first estimate of ICPP incidence in mainland France in 2011-2013. ICPP incidence displayed
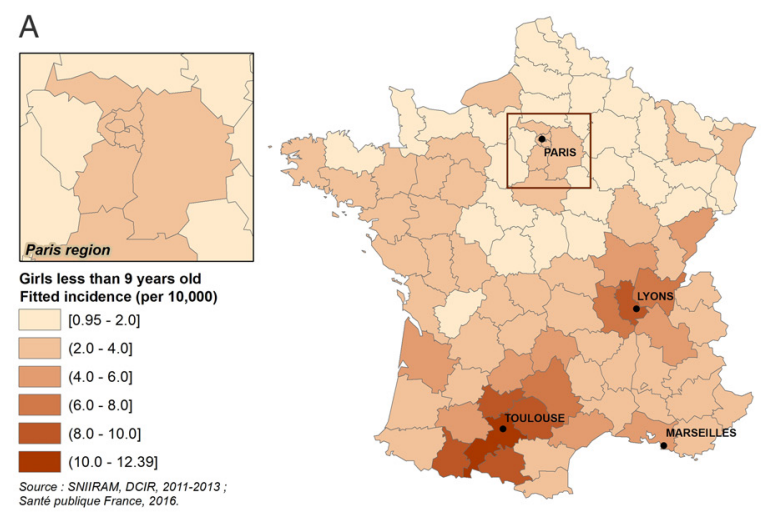

B

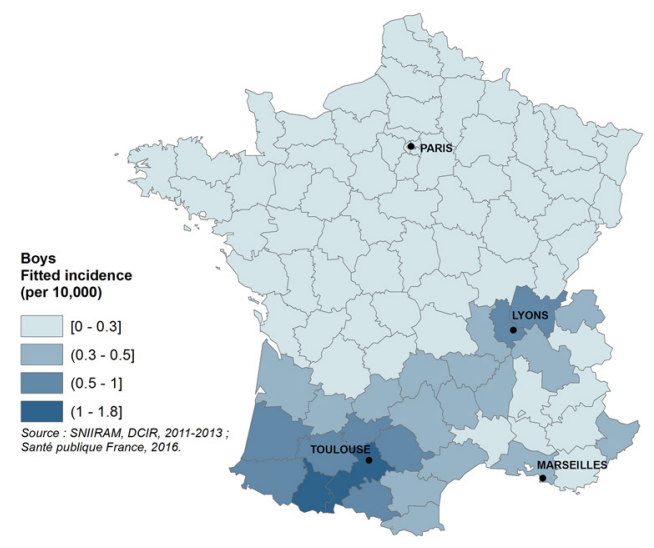

Figure 2

Fitted incidence rates for ICPP in French départements in girls under the age of nine years (2A) and boys under the age of 10 years (2B) at first delivery of $\mathrm{GnRH}$ agonist, based on drug reimbursement data for 2011-2013. A full colour version of this figure is available at https://doi.org/10.1530/EJE-17-0379. 

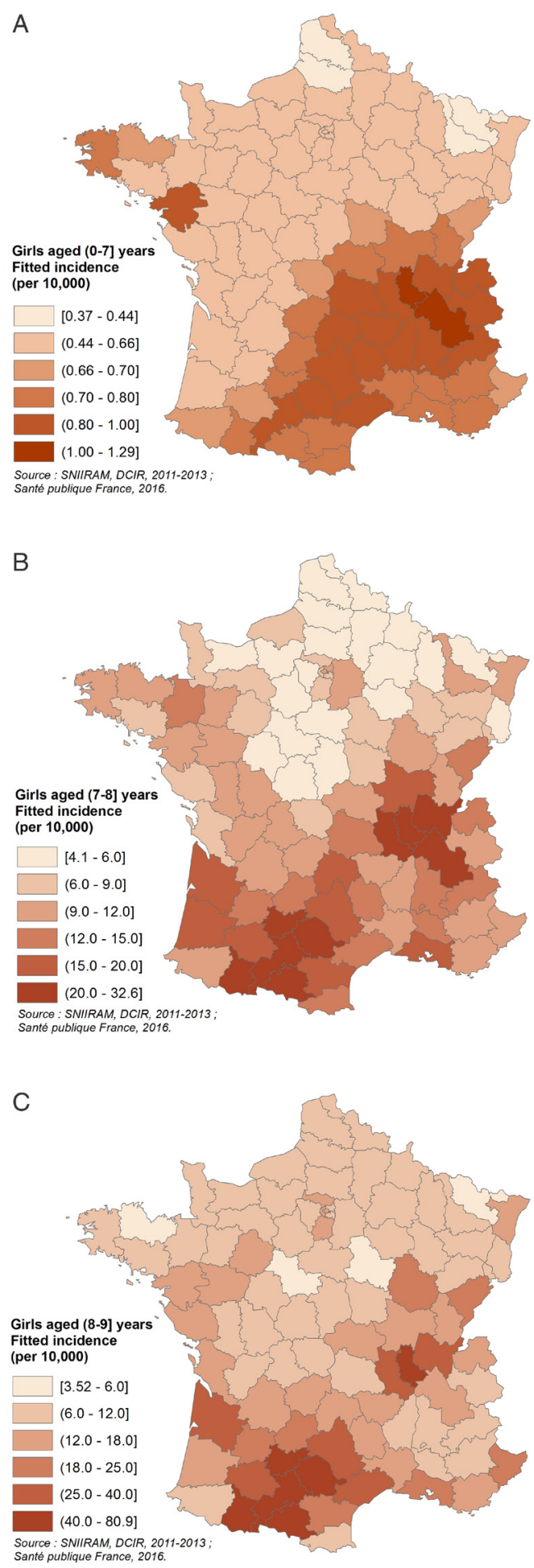

purely spatial heterogeneity, with similar geographic patterns for girls and boys, suggesting similar risk factors for both sexes. The strengths of this study are the nationwide completeness of the data, with a populationbased and exhaustive database, the use of a specific indicator for CPP treatment, the link to hospital data to exclude known causes of CPP and spatial modeling at the départment scale.

\section{National incidence}

In girls, the estimated national incidence of ICPP in France is slightly higher than the rough estimate for female PP of $1 / 5000$ to $1 / 10000$ girls obtained by the interpolation of US data. To our knowledge, only three epidemiological studies worldwide have actually estimated national incidences of PP. Our results are closest to the Danish findings based on national registries, with the same age criteria for inclusion (9). Over the 1993-2001 study period, the annual incidence of PP in Denmark was between 1.5 and 2.9/10 000 in girls under the age of nine years, and close to $0.25 / 10000$ in boys under the age of 10 years. The female-to-male sex ratio was 15 . Both these findings are consistent with the gradual decrease in male-to-female sex ratio for CPP observed since the 1990s, possibly due to an increase in the frequency of ICPP in girls (6).

In Spain, an observational study including 34 pediatric endocrinology units estimated the annual incidence of CPP (for girls and boys considered together) at between 0.002 and 0.107/10 000 in 2008-2009 (8), a frequency of one-twentieth that is reported here. The age criteria were set one year below ours. As $49 \%$ of the female cases in our study belonged to the highest age group (Table 1), this difference in inclusion criteria may account, at least in part, for the differences in results.

The third study, carried out in South Korea, also used drug reimbursement information from the national health insurance database (7). The authors found a significant increase in the incidence of CPP from 2004 to 2010: from 0.33 to $5.04 / 10000$ in girls and from 0.03 to $0.12 / 10000$ in boys. The age criteria were more restrictive in the Korean study, but we excluded known causes of CPP, and these factors may partly account for the differences between the two studies. An increase in incidence with age was also observed in both sexes (Table 1) in the Korean and Danish studies.

Overall, few epidemiological data are currently available for this condition and the methods used in different studies are not entirely comparable. Our results, based on exhaustive nationwide data, are consistent org/10.1530/EJE-17-0379. 
with former rough estimates and are of a similar order of magnitude to the data reported for Denmark and South Korea.

\section{Spatial trends}

Several hypotheses other than differences in medical practices can be put forward to explain the marked spatial heterogeneity of ICPP incidence in France. The most heavily populated part of France, the Parisian Basin, which houses one-fifth of the French population and has a particularly high concentration of health care facilities and hospital teams of pediatric endocrinologists, had a low-to-average incidence of ICPP.

Genetic factors are involved in PP (12) and ethnicity may also have an effect. Age at menarche and onset of breast development has been reported to decrease along a north-to-south gradient (6). There have been particularly high levels of immigration from Spain to the Midi-Pyrenees in recent decades (21). Even if the incidence of CPP in Spain appears to be lower than that in France (8), this aspect merits investigations in further studies. The RhôneAlpes region also has a large population of immigrants of various origins, although the proportion of immigrants remains lower than that in the Parisian Basin (22).

Nevertheless, our results may partly reflect the northsouth gradient in age at the onset of puberty, at the scale of France, and this pattern may also reflect the influence of environmental factors. One recent French cohort study investigated the effect of latitude and exposure to ultraviolet radiation on self-reported age at menarche and suggested that light exposure in childhood may influence sexual maturation in women (11). To our knowledge, this factor has not been studied in boys. However, the north-south gradient is discordant for ICPP incidence in Southeast France, and this factor is unlikely to account for the large differences observed.

The known or suspected causal factors for ICPP are being overweight $(1,2,23)$, being adopted $(24,25)$ and paternal absence $(26,27)$. The areas with a high ICPP incidence did not have particularly high rates of overweight individuals (28). Unfortunately, no geographic data were available for adoption.

The purely spatial heterogeneity observed suggests that the risk factors have a particular spatial distribution, potentially consistent with an environmental factor present over large areas. The role of environmental pesticide exposure should be considered, because such a role is consistent with the EDC hypothesis. Indeed, many pesticides behave as endocrine disruptors, and some are persistent in air, soil and water (29). Our results are also consistent with extensive industrial exposure to chemicals acting as EDCs or with still unknown exposure to factors in the environment.

Pesticides are widely used in France, especially in vineyards and orchards (30), and there is documented evidence of biological exposure of the general population to organochlorines, organophosphates and pyrethroids (31). The Midi-Pyrenees region is densely populated and has the largest number of agricultural holdings, mostly small in size, with diverse activities (wine, fruits, vegetables and cereal) of any region in France; it also has the second largest area under agriculture of any region in France (32). Interestingly, a marked trend toward decreasing sperm quality was recently observed in this area (33). The Rhône-Alpes region, also densely populated, is sometimes referred to as the 'orchard of France' as it has a larger area under fruit trees than any other region in France, mostly on small holdings (34). It also includes large industrialized areas near the Rhône, in the so-called chemical corridor. Other regions are also highly agricultural, with a high proportion of vineyards and orchards (e.g. around Bordeaux, Montpellier and Nice); yet, they do not display high ICCP incidences. However, crop protection practices and chemical use differ between agricultural regions, depending on climate and the pests present (35).

Pesticides are already thought to favor the development of TDS reproductive health disorders in men, and ovarian digenesis syndrome in women mirrors TDS (14). The most plausible causal relationship between EDC exposure and PP involves principally polybrominated biphenyls and cosmetics $(5,29)$. Animal and human data, although suggestive, remain inconclusive for pesticides, although only a small number of pesticides have been studied and mixture effects may also add to the complexity of the situation (36).

Finally, these descriptive findings highlight the need for further studies to explore hypothetical causal relationships in depth. We now plan to develop nationwide geographic indicators of environmental exposure usable at a relevant scale for this purpose.

\section{Limitations}

We estimated ICCP incidence with an exhaustive indicator based on the first drug delivery of GnRH agonists. This indicator does not account for undiagnosed or untreated ICCP. Conversely, some of the children might not 
constitute real cases of ICCP, because some girls might be over the age of eight years and some boys might be over the age of nine years at the onset of pubertal development.

As we considered a time lag of up to one year, from clinical onset to the first drug delivery, some of the girls with a first drug delivery after the age of eight years may have a puberty onset after eight years and may be at an advanced stage of puberty. The same is true for boys over the age of nine years. However, this time lag also takes into account late diagnosis, which is especially frequent for boys.

Girls with an onset of puberty before the age of seven years may have their first drug delivery before seven or eight years of age. Thus, for girls having their first drug delivery at an age of more than eight years, and perhaps for some of the girls of seven to eight years, the unusual practices we identified in some regions might limit the robustness of our findings for spatial trends.

The hospital team recruiting patients through an upstream network explained that they decided to use this approach because it was the best way to deal with the many children sent to them from all over the region. It therefore remains unclear whether this process was a consequence or a cause of the higher incidence observed in the region. Trained practitioners might be able to improve PP detection. However, according to clinicians from other regions, mothers usually detect PP early in girls and consult a doctor directly, because the signs are obvious and information is widely available through the media. Conversely, late detection is usual in boys, with even trained doctors not systematically examining the testis.

The influence of the first-voided urinary LH determination method used for ICPP diagnosis in another region merits attention. One recent study suggested that the sensitivity of this method for detecting true CPP was higher than that of the GnRH test, at $83 \%$ vs $72 \%$ (37). The use of this test would therefore probably result in about $10 \%$ more treated cases in this region than elsewhere. This practice alone could not, therefore, account for all the excess ICPP cases. Close surveillance for the detection of progressive CPP might result in fewer treated cases in a region with low incidence, but, conversely, a true low incidence would make it possible to carry out more consultations per child.

Overall, according to clinicians, the spatial results for boys and girls under the age of seven years were especially robust. In girls above the age of seven or eight years, unusual practices might contribute to higher/lower local ICPP incidences. However, as the spatial pattern was mostly consistent within age groups in girls, and very similar in boys, with a wide range of incidence rates recorded, this potential contribution would probably be marginal in the strong geographic pattern observed.

\section{Conclusion}

We used an epidemiological indicator available nationwide to estimate the national incidence of ICPP in boys and girls in France in 2011-2013 and to analyze spatial trends at the département scale. The French incidences of ICPP reported here are of a similar order of magnitude to those reported in the few comparable studies carried out in other countries. We found a marked pattern of purely spatial heterogeneity in ICPP incidence that was similar in boys and girls. Environmental causes are candidates to explain this pattern and should be investigated further.

Supplementary data

This is linked to the online version of the paper at https://doi.org/10.1530/ EJE-17-0379.

\section{Declaration of interest}

Dr Carel reports receiving grant funding from Ipsen and travel support from Sandoz. The other authors declare that there is no conflict of interest that could be perceived as prejudicing the impartiality of the research reported.

\section{Funding}

The study was funded by Santé publique France.

\section{Author contribution statement}

J L M, A R, J L and J C conceived the study. A R collected data from the Sniiram and Insee. A L T conducted the statistical analysis. P D C generated the maps, and $J \mathrm{~L} M$ and $A \mathrm{R}$ performed the clinical interviews. $J \mathrm{~L} M$ coordinated the study and conducted the interpretation of data. J L M and $A R$ drafted the manuscript. $J L$ and $J C$ reviewed the manuscript for important intellectual content. All authors approved the final version submitted for publication.

\section{Acknowledgements}

Many thanks to the members of the five hospital teams we interviewed: Sabine Baron, Emmanuelle Caldagues, Marylène Caquard, Audrey Cartault, Maryse Cartigny, Stéphanie Danner, Iva Gueorguieva, Isabelle Hazart, Christine Lefèvre, Christèle Le Guen, Marie Mansilla, Marc Nicolino, Bénédicte Nold, Catherine Pienkowski, Benedicte Riou, Sylvie Rossignol, Sylvie Soskin, Chantal Stuckens, Carine Villanueva and Catherine Wemeau. The authors thank Christophe Perrey for helping them to prepare the 
standardized guide used in the clinical interviews and their colleagues at Santé publique France for their support: Georges Salines, Agnès Lefranc, Sebastien Denys, Nathalie Velly, Mélina Le Barbier, Edwige Bertrand, Agnès Guillet and Marjorie Boussac.

\section{References}

1 Ong KK, Ahmed ML \& Dunger DB. Lessons from large population studies on timing and tempo of puberty (secular trends and relation to body size): the European trend. Molecular and Cellular Endocrinology 2006 254-255 8-12. (https://doi.org/10.1016/j.mce.2006.04.018)

2 Kaplowitz PB. Link between body fat and the timing of puberty. Pediatrics 2008121 S208-S217. (https://doi.org/10.1542/peds.20071813F)

3 Aksglaede L, Juul A, Olsen LW \& Sorensen TI. Age at puberty and the emerging obesity epidemic. PLOS ONE 20094 e8450. (https://doi. org/10.1371/journal.pone.0008450)

4 French Government. Stratégie nationale sur les perturbateurs endocriniens, 2014. (Available at: http://www.developpementdurable.gouv.fr/IMG/pdf/2014-04-29_Strategie_Nationale_ Perturbateurs_Endocriniens.pdf)

5 Le Moal J, Sharpe RM, Jvarphirgensen N, Levine H, Jurewicz J, Mendiola J, Swan SH, Virtanen H, Christin-Maitre S, Cordier S et al. Toward a multi-country monitoring system of reproductive health in the context of endocrine disrupting chemical exposure. European Journal of Public Health 201626 76-83. (https://doi.org/10.1093/ eurpub/ckv153)

6 Parent AS, Teilmann G, Juul A, Skakkebaek NE, Toppari J \& Bourguignon JP. The timing of normal puberty and the age limits of sexual precocity: variations around the world, secular trends, and changes after migration. Endocrine Reviews 200324 668-693. (https:// doi.org/10.1210/er.2002-0019)

7 Kim SH, Huh K, Won S, Lee KW \& Park MJ. A significant increase in the incidence of central precocious puberty among Korean girls from 2004 to 2010. PLoS ONE 201510 e0141844. (https://doi.org/10.1371/ journal.pone.0141844)

8 Soriano-Guillen L, Corripio R, Labarta JI, Canete R, Castro-Feijoo L, Espino R \& Argente J. Central precocious puberty in children living in Spain: incidence, prevalence, and influence of adoption and immigration. Journal of Clinical Endocrinology and Metabolism 201095 4305-4313. (https://doi.org/10.1210/jc.2010-1025)

9 Teilmann G, Pedersen CB, Jensen TK, Skakkebaek NE \& Juul A. Prevalence and incidence of precocious pubertal development in Denmark: an epidemiologic study based on national registries. Pediatrics 2005116 1323-1328. (https://doi.org/10.1542/peds.20050012)

10 Carel JC \& Leger J. Clinical practice. Precocious puberty. New England Journal of Medicine 2008358 2366-2377. (https://doi.org/10.1056/ NEJMcp0800459)

11 Dossus L, Kvaskoff M, Bijon A, Engel P, Verdebout J, Fervers B, Boutron-Ruault MC, Clavel-Chapelon F \& Mesrine S. Latitude and ultraviolet radiation dose in the birthplace in relation to menarcheal age in a large cohort of French women. International Journal of Epidemiology 201342 590-600. (https://doi.org/10.1093/ije/dyt007)

12 Latronico AC, Brito VN \& Carel JC. Causes, diagnosis, and treatment of central precocious puberty. Lancet Diabetes Endocrinol 20164 265-274. (https://doi.org/10.1016/S2213-8587(15)00380-0)

13 Abreu AP, Dauber A, Macedo DB, Noel SD, Brito VN, Gill JC, Cukier P, Thompson IR, Navarro VM, Gagliardi PC et al. Central precocious puberty caused by mutations in the imprinted gene MKRN3. New England Journal of Medicine 2013368 2467-2475. (https://doi. org/10.1056/NEJMoa1302160)

14 Buck Louis GM, Gray LE Jr, Marcus M, Ojeda SR, Pescovitz OH, Witchel SF, Sippell W, Abbott DH, Soto A, Tyl RW et al. Environmental factors and puberty timing: expert panel research needs. Pediatrics 2008121 S192-S207. (https://doi.org/10.1542/peds.1813E)

15 Bourguignon JP, Rasier G, Lebrethon MC, Gerard A, Naveau E \& Parent AS. Neuroendocrine disruption of pubertal timing and interactions between homeostasis of reproduction and energy balance. Molecular and Cellular Endocrinology 2010324 110-120. (https://doi.org/10.1016/j.mce.2010.02.033)

16 Sorensen K, Mouritsen A, Aksglaede L, Hagen CP, Mogensen SS \& Juul A. Recent secular trends in pubertal timing: implications for evaluation and diagnosis of precocious puberty. Hormone Research in Paediatrics 201277 137-145. (https://doi.org/10.1159/000336325)

17 Tuppin P, de RL, Weill A, Ricordeau P \& Merliere Y. French national health insurance information system and the permanent beneficiaries sample. Revue d'Épidémiologie et de Santé Publique 201058 286-290.

18 Rigou A, Le Moal J, Léger J, Le Tertre A \& Carel JC. A cost-effective method to monitor precocious puberty nationwide in France. European Journal of Pediatrics 2017 Epub. (https://doi.org/10.1007/s00431-0173012-y)

19 Besag J, York J \& Mollie A. Bayesian image restoration, with two applications in spatial statistics. Annals of the Institute of Statistical Mathematics 199143 1-59. (https://doi.org/10.1007/BF00116466)

20 Carel JC, Eugster EA, Rogol A, Ghizzoni L, Palmert MR, Group E-LGACC, Antoniazzi F, Berenbaum S, Bourguignon JP, Chrousos GP et al. Consensus statement on the use of gonadotropinreleasing hormone analogs in children. Pediatrics 2009123 e752-e762. (https://doi.org/10.1542/peds.2008-1783)

21 Insee. Midi-Pyrennées Atlas des populations immigrées. Insee (National institute of statistics and economic studies). (Available at: https://www.epsilon.insee.fr/jspui/bitstream/1/14293/1/DEMP_ atlas_0405.pdf)

22 Ministère de l'intérieur. Atlas national des populations immigrées. 2013. (Available at: http://www.immigration.interieur.gouv.fr/ Archives/Les-archives-du-site/Archives-Statistiques-etudes-etpublications/Atlas-national-des-populations-immigrees)

23 Michalakis K, Mintziori G, Kaprara A, Tarlatzis BC \& Goulis DG. The complex interaction between obesity, metabolic syndrome and reproductive axis: a narrative review. Metabolism 201362 457-478. (https://doi.org/10.1016/j.metabol.2012.08.012)

24 Teilmann G, Pedersen CB, Skakkebaek NE \& Jensen TK. Increased risk of precocious puberty in internationally adopted children in Denmark. Pediatrics 2006118 e391-e399. (https://doi.org/10.1542/peds.2005-2939)

25 Baron S, Battin J, David A \& Limal JM. Precocious puberty in children adopted from foreign countries. Archives de Pédiatrie 20007 809-816.

26 Bogaert AF. Age at puberty and father absence in a national probability sample. Journal of Adolescence 200528 541-546. (https:// doi.org/10.1016/j.adolescence.2004.10.008)

27 Deardorff J, Ekwaru JP, Kushi LH, Ellis BJ, Greenspan LC, Mirabedi A, Landaverde EG \& Hiatt RA. Father absence, body mass index, and pubertal timing in girls: differential effects by family income and ethnicity. Journal of Adolescent Health 201148 441-447. (https://doi. org/10.1016/j.jadohealth.2010.07.032)

28 Inserm KH, Roche. Obepi, 2012. (Available at: http://www.roche.fr/ content/dam/roche_france/fr_FR/doc/obepi_2012.pdf)

29 Bergman A, Heindel JJ, Jobling S, Kidd KA \& Zoeller RT. State of the science of endocrine disrupting chamicals-2012. pp 1-296. (Available at: http://www.who.int/ceh/publications/endocrine/en/)

30 Inserm. Pesticides et santé. Synthèse et recommandations. pp 1-95. Ed Inserm, 2013. (Available at: www.inserm.fr/content/ download/72647/562921)

31 Frery NGL, Saoudi A, Garnier R, Zeghnoun A \& Bidondo M-A. Exposition de la population francaise aux substances chimiques de l'environnement, tome 2. pp 1-176. Ed InVS, 2013.

32 Ministère de l'Agriculture. Midi-Pyrenées. In Graphagri Regions, 2014. (Available at: http://agreste.agriculture.gouv.fr/IMG/pdf/ Gar14p260-267.pdf) 
33 Le Moal J, Rolland M, Goria S, Wagner V, De Crouy-Chanel P, Rigou A, De Mouzon J \& Royère D. Semen quality trends in French regions are consistent with a global change in environmental exposure. Reproduction 2014147 567-574. (https://doi.org/10.1530/ REP-13-0499)

34 Agriculture Mo. Rhone-Alpes. In Graphagri Regions, 2014. (Available a0074: http://agreste.agriculture.gouv.fr/IMG/pdf/Gar14p332-339.pdf)

35 Bisault L. A chaque vignoble ses traitements. AGRESTE La statistique agricole 2009. (Available at: http://agreste.agriculture.gouv.fr/IMG/ pdf_primeur230.pdf)
36 Kortenkamp A. Low dose mixture effects of endocrine disrupters: implications for risk assessment and epidemiology. International Journal of Andrology 200831 233-240. (https://doi.org/10.1111/j.13652605.2007.00862.x)

37 Zung A, Burundukov E, Ulman M, Glaser T, Rosenberg M, Chen M $\&$ Zadik Z. The diagnostic value of first-voided urinary LH compared with GNRH-stimulated gonadotropins in differentiating slowly progressive from rapidly progressive precocious puberty in girls. European Journal of Endocrinology 2014170 749-758. (https://doi. org/10.1530/EJE-14-0010)

Received 10 May 2017

Revised version received 16 August 2017

Accepted 8 September 2017 